\title{
Parvovirus B19 DNA detection in treatment-naïve HIV anemic patients in Lagos, Nigeria: a case control study
}

\author{
Oluwaseyi Sedowhe Ashaka ${ }^{1}$, Olumuyiwa Babalola Salu ${ }^{2,3}$, Ayorinde Babatunde James ${ }^{3,4}$, \\ Akeeb Oriowo Bola Oyefolu ${ }^{5}$, AbdulAzeez Adeyemi Anjorin ${ }^{5}$, Bamidele Oludare Oke ${ }^{6}$, \\ Mercy Remilekun Orenolu ${ }^{3}$, Sunday Aremu Omilabu ${ }^{2,3}$
}

1. Medical Microbiology and Parasitology, College of Health Sciences, University of Ilorin, Ilorin, Nigeria.

2. College of Medicine of the University of Lagos, Medical Microbiology and Parasitology P.M.B. 12003, Idi-Araba, Surulere Lagos, Nigeria.

3. College of Medicine of the University of Lagos, Centre for Human and Zoonotic Virology (CHAZVY)

P.M.B. 12003, Idi-Araba Surulere Lagos, Nigeria.

4. Department of Biochemistry and Nutrition, Nigerian Institute of Medical Research, Yaba, Lagos, Nigeria.

5. Department of Microbiology, Lagos State University, Ojo P.M.B. 1087, Apapa, Lagos, Nigeria.

6. Clinical Sciences Division, Nigerian Institute of Medical Research, Yaba, Lagos.

\begin{abstract}
Background: Parvovirus B19 (B19) has tropism for cells of the erythroid lineage, which may lead to transient inhibition of erythropoiesis. Several studies and case reports suggested that B19 infection may contribute significantly to severe chronic anemia in HIV infected persons.
\end{abstract}

Objective: To detect parvovirus B19 DNA in treatment-naïve HIV patients.

Methods: This was a case control retrospective study. One hundred nineteen anemic and 81 non-anemic treatment-naïve HIV infected patients participated in the study at the Lagos University Teaching Hospital, Lagos, Nigeria. Polymerase chain reaction was used to detect B19 DNA.

Results: Out of 200 patients analysed, 13(6.5\%) had parvovirus B19 DNA. Eight HIV patients with anemia had B19 DNA while five non-anemic HIV patients had B19 DNA. This suggests that the presence of B19 DNA in the blood of HIV positive individuals may contribute to anemia because the majority $(61.5 \%)$ who were positive for B19 DNA had anemia as compared to the non-anemic control group (38.5\%).

Conclusion: This study shows that the presence of B19 DNA in anemic HIV infected patients is not associated with chronic anaemia in HIV infection because no significant association exist.

Keywords: Parvovirus B19, anemia, human immunodeficiency virus, polymerase chain reaction.

DOI: https://dx.doi.org/10.4314/ahs.v20i1.27

Cite as: Ashaka OS, Salu OB, James AB, Oyefolu AOB, Anjorin AA, Oke BO, et al. Parvovirus B19 DNA detection in treatment-naïve HIV anemic patients in Lagos, Nigeria: a case control study. Afri Health Sci. 2020;20(1):219-26. https:/ / dx.doi.org/10.4314/abs.v20i1.27

\section{Corresponding author:}

Oluwaseyi Sedowhe Ashaka,

Medical Microbiology and Parasitology, College

of Health Sciences, University of Ilorin, Ilorin.

Email: ashakseyi@gmail.com

\section{Introduction}

Human parvovirus B19 (B19V) is a small DNA virus that lacks an envelope. It is a member of the family Parvoviridae within the genus Erythrovirus ${ }^{1}$. B19V is an autonomously replicating virus; its complete life cycle is supported only in rapidly dividing erythroid progenitor cells.

(C) 2020 Ashaka OS et al. Licensee African Health Sciences. This is an Open Access article distributed under the terms of the Creative commons Attribution License (https://creativecommons.org/licenses/BY/4.0), which permits unrestricted use, distribution, and reproduction in any medium, provided the original work is properly cited. 
B19V has two structural proteins, viral protein 1 (VP1) and viral protein 2 (VP2). The viral capsid which is made up of 60 capsomeres contains mainly VP2 while VP1 accounts for only about 5 percent of the capsid protein. The VP1 unique region extends from the capsid and contains many linear epitopes recognized by neutralizing antibodies ${ }^{2}$. Antibody production to the VP1 minor capsid protein is produced after the first week of infection and forms the main antibody in individuals after recovery from acute infection.

$\mathrm{B} 19 \mathrm{~V}$ is a significant pathogen which causes asymptomatic childhood exanthem erythema infectious (fifth disease), post-infectious arthropathy in adults, transient aplastic crisis in individuals with underlying hemolytic disorders and chronic anemia in immunocompromised hosts one of which are HIV/AIDS patients. Infection with parvovirus B19 causes lysis in permissive erythroid progenitor cells which may result in reticulocytopenia ${ }^{3}$. The transmission of B19V occurs mainly via respiratory droplets but it can also be spread by contaminated blood, organ transplantation and vertical transmission from mother to fetus ${ }^{4}$. The virus can be detected in the saliva in the acute phase of infection. Also, experimental transmission of the virus via nasal inoculation in animal models has been observed ${ }^{5}$.

During infection, B19V is disseminated throughout the body and enters the bone marrow microenvironment, producing generalized erythroblast infection ${ }^{4}$. However, the lymphopenia, neutropenia and thrombocytopenia that occur during the acute viremic phase are not significant. The etiology of the thrombocytopenia found in B19V infection can be partly explained by the existence of viral proteins which may be toxic to cell populations that are non-permissive for viral DNA replication ${ }^{6}$. Persistent low-titer viremia accompanied by B19V related chronic anemia has been observed in patients with various types of immunosuppression who may not be able to clear B19V effectively.

Research has shown the presence of antibodies to B19V in the African setting with a prevalence rate of between $27-63 \%{ }^{7-9}$. Studies in Ghana and South Africa have detected varied genotypes of B19V DNA in circulation which gave evident indication that this virus exist in the
African population ${ }^{10-11}$. In Africa, different etiologies contribute to the burden of anemia especially among the immunocompromised and the contribution of B19V among this population is yet to be ascertained.

In immunocompromised patients such as those receiving immunosuppressive therapy, those with congenital immune deficiencies or those infected with HIV infection, parvovirus B19 infection causes chronic persistent infections which may result in severe anemia due to inability to produce neutralizing antibodies on the conformation-dependent neutralizing epitopes, and consequent persistence of virus replication ${ }^{2}$.

Anemia is the most common hematologic abnormality observed in HIV-infected patients ${ }^{12}$. It has been observed that there are many causes of anemia in these patients which may be from infectious or non-infectious origin ${ }^{13}$. Diagnosis of B19V is important in immunocompromised patients because of the effects of chronic B19V viremia which may persist due to the failure to produce neutralizing antibodies to the virus ${ }^{14}$.

From reports, it has been observed that up to 60 to $80 \%$ of $\mathrm{HIV}$-infected persons present with anemia ${ }^{10}$. This percentage increases with advancing HIV infection, therefore anemia has been implicated as the most common hematologic abnormality observed in HIV-infected patients and it is a significant predictor of progression to AIDS or death ${ }^{16,17}$. Although, the etiology of anemia in HIV infection remains largely unclear, in recent years, several attempts have been made to elucidate the mechanisms leading to HIV-associated anemia. As the causes of anemia in HIV patients are multifactorial, there is need for the detection of parvovirus B19 in these patients because it may be a probable cause of anemia ${ }^{14}$.

It is known that antiretroviral drugs such as Zidovudine, ganciclovir, trimethoprim-sulfamethoxazole and or antineoplasm or lymphoma may contribute to the hematoxic effect observed among HIV infected individuals ${ }^{13}$. Therefore, in this study our focus was on treatment naïve HIV infected persons to exclude possible confounders of anemia.

In this study we used PCR to detect parvovirus B19VDNA in 119 anemic and 81 non-anemic treatment-naïve HIV infected individuals in order to determine the contribution of parvovirus B19 to anemia among the study population. 


\section{Methods}

Study site: This study was conducted at the AIDS Prevention Initiative in Nigeria (APIN) clinic at the Lagos University Teaching Hospital (LUTH) in Nigeria. The APIN clinic attends daily to an average of 250 old and new patients (adults and children). Antiretroviral drugs are dispensed on a monthly basis to about 8,000 registered HIV infected patients including men, pregnant and non-pregnant women and children from different parts of Nigeria.

Study design: This study was a case control retrospective study carried out on patients recruited to the HIV management program in LUTH. Core data on sex, date of birth, date of first visit, confirmatory test of HIV status, hemoglobin concentration, CD4 count and history of drug use were obtained from the patients' medical record.

Inclusion Criteria: Specimen of HIV infected patients 16 years and above with corresponding record in the HIV clinic who have been introduced to HAART regimen.

Exclusion criteria: Specimen of HIV infected patients that are below 16 years, who have been introduced to HAART regimen, pregnant and lactating women as well as those with history of chronic kidney disease, known sickle cell disease and patients whose records indicated recent blood transfusion within one year were excluded from the study.

Sample size: The sample size for this study was calculated using Fisher's formula $n=z^{2} p q / d^{2}$ to be 200 using a prevalence in the study done by Iwalokun et al. ${ }^{8}$.

Plasma samples of patients stored between January and September, 2011 were retrieved for this study. A total of 200 consecutive samples that met the inclusion criteria were obtained. The samples were categorized using hemoglobin concentration values obtained from patients records. Patients that matched our definition of anemia $(\mathrm{Hb}<10 \mathrm{~g} / \mathrm{dl})$ were treated as case group while patients with $\mathrm{Hb}=$ or $>10 \mathrm{~g} / \mathrm{dl}$ were treated as control group ${ }^{18}$. A total 119 and 81 samples retrieved were anemic non-anemic respectively. Classification based on gender identified samples of 64 males and 136 females. The mean age of participants was 36 years (range 16-67 years). Plasma samples were stored at $-20^{\circ} \mathrm{C}$ before testing.

Polymerase Chain Reaction: Specimens retrieved were transported to Virology Unit Laboratory at the College of Medicine, University of Lagos where molecular anal- ysis was done. Nucleic acid was extracted from patient plasma using QIAamp DNA Blood Mini Kit (Qiagen, Hilden, Germany) according to the manufacturer's instruction. The detection of B19V-DNA was tested by polymerase chain reaction (PCR) as described previously using primer pairs specific for the NS1/VP1u-region -coding regions ${ }^{19}$. PCR was carried out using both forward and reverse primers respectively was performed, e1855f- CACTATGAAAACTGGGCAA, B19-R1- GGGAACTTCCGGCAAACTTCCTTG ${ }^{19,20}$. The PCR products were analysed in a 1.5\% agarose gel stained with SYBR ${ }^{\circledR}$ Safe DNA Gel Stain (Life Technologies, New York, USA). Prior to analysis of specimen PCR optimization was carried out using positive control from the laboratory. In order to prevent assay contamination, sample processing (DNA-extraction, template preparation, centrifugation, aliquoting, and master mix preparation) and PCR-amplification were performed in dedicated laboratory facilities certified for molecular diagnostics and especialy for PCR, using standard precautions.

Ethical Consideration: This study was conducted in accordance with the Declaration of Helsinki, and the protocol was approved by the research ethics committee and review board, Lagos University Teaching Hospital (LUTH), Idi-araba, Lagos state, Nigeria. All routine clinical and therapeutic data were coded and analyzed anonymously throughout the study. Informed consent was waived for the study.

Statistical Analysis: The generated data was systematically analyzed as appropriate for means, proportion and chi-square test using SPSS software version 18 (California Inc.). A one-sided $\mathrm{P}<0.05$ was considered statistically significant for chi-square (used to determine the differences between the groups).

Funding: The study had no external funding source.

\section{Results}

A total of 200 anti-retroviral naïve HIV individuals which comprised 119 anemic and 81 non-anemic participants were tested for B19V-DNA. Western blot technique was used confirm HIV status of these individuals. In this study, 8 of 119 anemic individuals $(6.72 \%)$ had B19V-DNA detectable by PCR, as compared to 5 of 81 non-anemic individuals $(6.17 \%)$ with no statistically significant association between both groups as shown in table 1.

African Health Sciences Vol 20 Issue 1, March, 2020 
Table 1: Parvovirus B19 DNA distribution among case and control subjects

\begin{tabular}{llllll}
\hline Sample Type & $\begin{array}{l}\text { B19 DNA } \\
\text { Positive }\end{array}$ & Number tested (N) & OR & $95 \% \mathrm{Cl}$ & $p$ \\
\hline Case (anemic) & 8 & 119 & & & \\
$\begin{array}{l}\text { Control (non- } \\
\text { anemic) }\end{array}$ & 5 & 81 & 1.096 & $0.345-$ & 0.877 \\
Total Number & 13 & 200 & & 3.477 & \\
\hline
\end{tabular}

$\mathrm{N}$ (total number of samples) $=200$

$X^{2}=0.024$

Note that: Case group hemoglobin concentration $\leq 9.9 \mathrm{~g} / \mathrm{dl}$

Control group hemoglobin concentration $>10 \mathrm{~g} / \mathrm{dl}$

In this study, anemia was defined by hemoglobin $(\mathrm{Hb})$ value less than or equal to $9.9 \mathrm{~g} / \mathrm{dl}$. The anemic HIV patients had a mean hemoglobin concentration of $8.49 \mathrm{~g} / \mathrm{dl}$ and a range of $5.0-9.8 \mathrm{~g} / \mathrm{dl}$ while those without anemia had hemoglobin range $10.0-17.2 \mathrm{~g} / \mathrm{dl}$ with a mean hemoglobin concentration of $11.57 \mathrm{~g} / \mathrm{dl}$.

The prevalence of $\mathrm{B} 19 \mathrm{~V}$ was found to be $6.5 \%$ (13 out of 200 patients). The age range of those who were ane- mic and non-anemic was $16-67$ years with a respective mean age of 36.5 years and 36.67 years. There were 64 men (32.0\%) (age range 25-67years) and 136 women $(68.0 \%)$ (age range 16-63 years) that were enrolled in the study out of whom 6 males and 7 females had detectable B19V-DNA by PCR. B19V prevalence of 34.6\% was observed among age group 31-40 years which was followed by $23.08 \%$ among age group $41-50$ years in the anemic and non-anemic controls as shown in table 2.

Table 2: Distribution of Parvovirus B19 DNA by age groups

\begin{tabular}{rcc}
\hline \multicolumn{1}{l}{$\begin{array}{l}\text { Age groups } \\
\text { (years) }\end{array}$} & $\begin{array}{l}\text { Parvovirus B19 } \\
\text { DNA }\end{array}$ & No. of Patients (N) \\
\hline $11-20$ & - & 5 \\
$21-30$ & 2 & 51 \\
$31-40$ & 5 & 82 \\
$41-50$ & 3 & 43 \\
$51-60$ & 2 & 16 \\
$61-70$ & 1 & 3 \\
\hline
\end{tabular}

$\mathrm{N}$ (total number of samples) $=200$ 
The immune status of patients evaluated among the HIV infected anemic group that had parvovirus DNA showed that majority had CD 4 count below 200 cells/ $\mu$ l when compared to the CD4 count of parvovirus DNA negative participants. The non-anemic group with parvovirus DNA had majority with CD4 count greater than 200 cells/ $\mu$ l when compared to the CD4 count of parvovirus
DNA negative participants. The CD4 count was grouped into those less than 200 cells $/ \mu$ l, between 200 and 499 cells $/ \mu \mathrm{l}$ and greater than 500 cells $/ \mu \mathrm{l}$ as depicted in figure 1. Mean CD4 count and range among the anemic group was 221.95 cells $/ \mu \mathrm{l}$ and $17-888$ cells $/ \mu \mathrm{l}$ respectively while mean CD 4 cell count and range was 260.38 cells/ $\mu$ and $11-808$ cells $/ \mu$ l respectively.

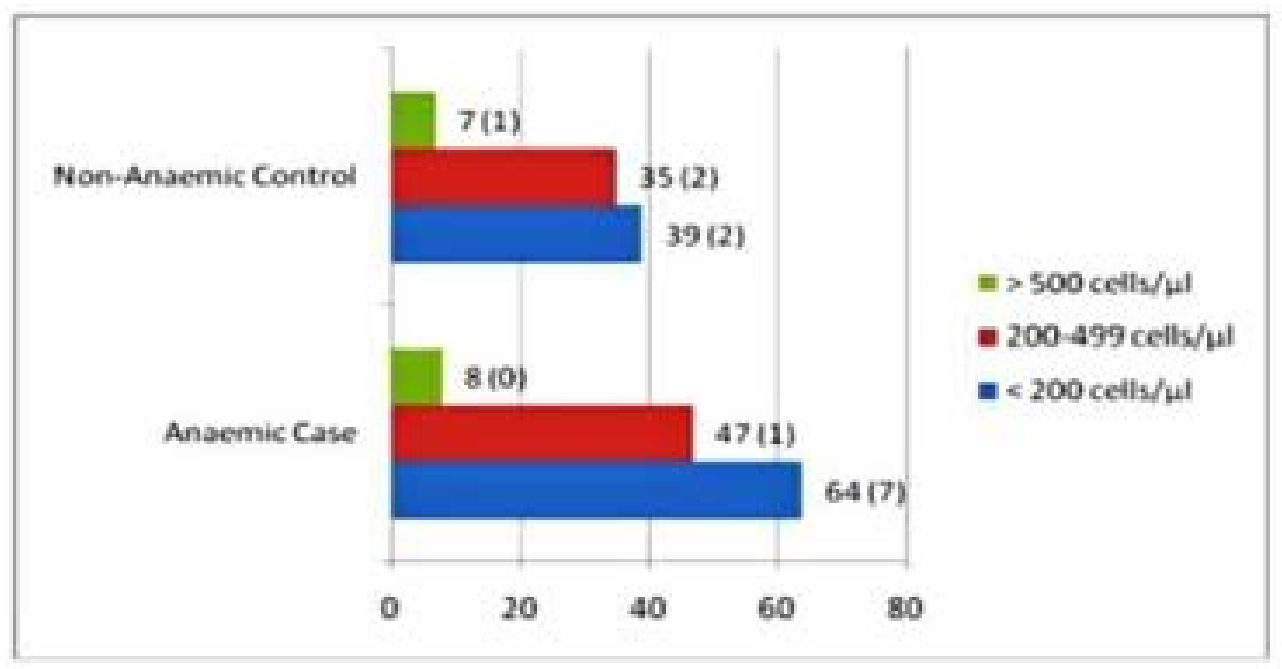

Figure 1: Range value of CD4 counts in anemic case and non- anemic control subjects. Note: Figures in bracket are those who had detectable Parvovirus B19 DNA in their blood

\section{Discussion}

Findings from our study showed that eight out of 119 anemic HIV positive patients $(6.72 \%)$ had detectable B19V-DNA while five out of $81(6.17 \%)$ non-anemic HIV positive patients had detectable B19V-DNA. This shows that both anemic and non-anemic HIV patients were exposed and infected with B19V. The extent to which $\mathrm{B} 19 \mathrm{~V}$ exacerbates anemia among the anemic group is not clearly seen from this study. The overall prevalence of B19V among HIV infected individuals in this study is high when compared with previous reports ${ }^{21-23}$.

Anemia is the most common hematologic abnormality associated with HIV infection, affecting $60 \%$ to $80 \%$ of patients in late- stage disease ${ }^{24-26}$. The prevalence and severity of anemia increase as the HIV infection advances to AIDS ${ }^{21}$. Several causes of anemia have been described in HIV patients such as drugs (zidovudine, ganciclovir, trimethoprim-sulfamethoxazole), lymphomas, direct effect of HIV on bone marrow cells and co-infection with mycobacteria, malaria or B19V ${ }^{27}$. In this study we excluded HIV patients on HAART because of the influ- ence some of these drugs may have on the status of anemia in the individual.

A study in Iran found the rate of B19V viremia in HIV patients without $\operatorname{IgG}$ to be $10.1 \%$ with a mean CD4 of $440.5 \pm 266.16$ cells $/ \mathrm{mm}^{3}{ }^{21}$. However, Patients with a CD 4 count greater than 300 cells/ $\mu$ l have been shown to be capable of producing neutralizing antibodies. Persistent infections are also more common among patients with advanced immunodeficiency ${ }^{27}$. Therefore, detecting IgG may not be definitive of persistent infection, considering the impaired ability to produce neutralizing antibodies against B19V especially in some HIV patients ${ }^{21}$. This study employed polymerase chain reaction technique to detect B19V-DNA in treatment-naïve HIV patients.

In this study, eight out of thirteen HIV patients with B19DNA had anemia and five out of 13 persons with B19DNA did not have anemia. This may imply that non-anemic individuals that had B19V may have recovered from infection related anemia which may still be present among the B19V infected anemic group. In our study, there is no statistically significant difference among the detection of B19V-DNA in both anaemic and non-anaemic groups. 
Our study corroborates earlier findings that parvovirus B19 in addition to HIV may increase the depletion of red blood cells in these patients ${ }^{28}$. In this study we found out that most of the HIV infected patients with CD4 count below 200 cells/ $\mu$ l that had parvovirus DNA detected in their blood had anemia while the non-anaemic individuals with CD4 counts above 200 cells/ $\mu$ l without evidence of immunosuppression showed no evidence of anaemia. This suggests that evidence of parvovirus B19 precipitating anemia may be observed among HIV patients who have evidence of immunosuppression. A study in Sweden had B19V-DNA detected by PCR in 5 of 69 anemic patients as compared to non-anemic controls with undetectable B19V-DNA ${ }^{26}$. The disparity observed could be as a result of the number of patients sampled in their study.

A study in Iowa, United States examined serial sera from 14 HIV patients with PCR, nine of fourteen had detectable viremia at some point by PCR. Four of the nine patients tested were serially positive for B19V-DNA in that study. Since all four patients with serially positive had severe anemia, the author concluded that B19V infection could be the cause of anemia in patients with HIV/ AIDS $^{29}$.

Another study in Washington, United States found 4 of 77 randomly selected HIV positive patients (5\%) positive for B19V-DNA by PCR. Five of 54 control patients (9\%) were also positive for B19V-DNA. The finding in this work is similar because of the detection of B19V-DNA in both anemic and non-anemic patients ${ }^{13}$. But our research work considered the CD4 counts both anemic and non-anemic HIV patients examined.

In this study we categorized anemia based on hemoglobin concentration less than or equal to $9.9 \mathrm{~g} / \mathrm{dl}$. However, some other studies defined anemia on hemoglobin concentration less than $9.0 \mathrm{~g} / \mathrm{dl}$. In this study we observed a mean CD4+ T cell count among anemic individuals was similar to some other studies done $\mathrm{e}^{3,30}$. The results obtained in this study differ in the prevalence rate of B19V which may be attributed to low CD4 counts of patients when compared with observations in other studies ${ }^{28,31}$. We inferred that the prevalence of B19V DNA in both anemic and non-anemic treatment-naïve HIV patients is an indication that this virus circulates among this population. The result of this study differs from a study that observed that $39 \mathrm{HIV}$ positive patients with anemia were
B19V viremia-negative by nested-PCR and concluded that $\mathrm{B} 19 \mathrm{~V}$ infection is an uncommon cause of anemia in the HIV positive population ${ }^{32}$.

The finding from this study is similar to a study by Vernazza et al, who described persistent B19V infection as an uncommon cause of anemia in HIV patients, due to preservation of an adequate humoral immune response until the late stages of HIV infection ${ }^{33}$. This appears true for our study because the stage of HIV infection cannot be assumed with the time the patient visits the hospital for testing for the first time.

Although, the prevalence of $\mathrm{B} 19 \mathrm{~V}$ was not determined in those who received HAART in this study, a study done in Iran found the prevalence of B19V significantly higher in treatment-naïve patients than patients who were undergoing HAART treatment ${ }^{28}$.

We suggest that in addition to parvovirus B19, HIV and other factors may be responsible for increase the depletion of red blood cells in the anemic group of patients especially among the immunosuppressed because B19V only account for approximately $7 \%$ of the anemia in this group.

There is need for careful selection of antiretroviral drug in HIV patient co-infected with parvovirus B19 in order to prevent exacerbated hematotoxic effects accompanied with severe aplastic anemia especially in patients progressing to AIDS.

However, knowing that B19V infects erythroid progenitor cells, HIV patient co-infected with parvovirus B19 needs to be given more priority attention especially in most developing countries that do not have a viral diagnostic algorithm for anemia.

We acknowledge the limitations of our study. We did not quantify and sequence parvovirus B19 DNA in this study to determine B19V genotype. Future research can take care of the detecting B19V-DNA among treatment naive HIV patients with evidence of immunosuppression to ascertain the implication of infection in this population as progression occurs to AIDS. Also, it will be important to study the transmission of parvovirus B19 among immunocompromised population.

\section{Conclusion}

This study characterizes the importance of parvovirus B19 DNA in HIV treatment naive patients that are anemic and non-anemic in Lagos, Nigeria. It was observed 
that the presence of B19 DNA in anemic HIV infected patients is not significantly associated with chronic anaemia in HIV infection.

\section{Competing interest}

The authors declare that there are no competing interests.

\section{Authors' contributions}

All the authors have contributed to this study in ways that comply to the ICMJE authorship criteria. All the authors have read and approved the final version of the manuscript.

\section{References}

1. Slavov SN, Kashima S, Silva-Pinto AC, Covas DT. Human parvovirus B19.General considerations and impact on patients with sickle-cell disease and thalassemia and on blood transfusions. Federation of European Microbiological Societies 2011, 62: 247-262

2. Young, NS, Brown K E. Parvovirus B19. New England Journal of Medicine 2004, 350: 586-597

3. de Azevedo KM, Setúbal S, Camacho L A B, Velarde L G C, de Oliveira S A. Seroepidemiological study of human parvovirus B19 among human immunodeficiency virus-infected patients in a medium-sized city in Rio de Janeiro, Brazil. Oswaldo Cruz, Rio de Janeiro 2009,104 (6): 901-904.

4. Heegaard E, Brown K. Human parvovirus B19. Clin Microbiol Rev 2002. 15: 485-505.

5. Gallinella G: Parvovirus B19 Achievements and Challenges. ISRN Virology 2013. 33 pages.

6. Pallier C, Greco A, Le Junter J, Saib A, Vassais I, Morinet F. The 3' untranslated region of B19 parvovirus capsid protein mRNAs inhibits its own mRNA translation in non-permissive cells. J Virol 1997, 71: 9482-9489. 7. Jegede A, Aminu M, Ella EE. Sero-prevalence of Human Parvovirus B19 among patients attending some hospitals in Kano metropolis, Nigeria Afr. J. ClnExper. Microbiol. 2014, 15(1): 21-26.

8. Iwalokun BA, Iwalokun SO, Hodonu SO. Seroprevalence of parvovirus B19 antbodies and evidence of viremia among Nigerian patents with sickle cell anaemia. J Biomed Res. 2013, 27(4):272-282.

9. Akyala IA, Amuta EU, Azua AT, Agieni AG. Parvovirus B19: Evaluation of Incidence, Prevalence and Risk Factors among Pregnant Women Attending Ante-Natal Clinic in Nasarawa State, North Central of Nigeria. Clinical Medicine and Diagnostics 2012, 2(5): 54-59.
10. Candotti D, Etiz N, Parsyan A, Allain JP. Identification and characterization of persistent human erythrovirus infection in blood donor samples. J. Virol. 2004, 78:12169-12178.

11. Corcoran C, Hardie D, Yeats J, Smuts H. Genetic Variants of Human Parvovirus B19 in South Africa: Cocirculation of Three Genotypes and Identification of a Novel Subtype of Genotype 1. Journal of Clinical Microbiology 2010, 48(1): 137-142.

12. Koduri P R. Parvovirus B19-related anemia in HIV-infected patients. AIDS Patient Care STDS 2000, 14: 7-11. 13. Abkowitz JL, Brown KE, Wood RW, Kovach N L, Green S W, Young N S. Clinical relevance of parvovirus B19 as a cause of anemia in patients with human immunodeficiency virus infection. J Infect Dis 1997, 176: 296273.

14. Frickhofen N, Abkowitz JL, Safford M, Berry JM, Antunez-de-Mayolo J, Astrow A, Cohen R, Halperin I, King L, Mintzer D, Cohen B, Young N S. Persistent B19 parvovirus infection in patients infected with human immunodeficiency virus type 1 (HIV-1): A treatable cause of anemia in AIDS. Ann Intern Med 1990, 113:926-933.

15. Zon LI, Groopman J E. Hematological manifestations of the human immunodeficiency virus (HIV). Seminar on Hematology1988, 25:205-8.

16. Spivak JL, Bender BS, Quinn T C. Hematological abnormalities in the acquired immune deficiency syndrome. Am J Med. 1984, 77:224-228.

17. Odunukwe N, Idigbe O, Kanki P, Adewole T, Onwujekwe D, Audu R, Onyewuche J. Hematological and biochemical response to treatment of HIV1 infection with a combination of nevirapine, stavudine and lamivudine in Lagos, Nigeria. Turkish Journal of Hematology 2005, 22: 125-131.

18. Table for Grading the Severity of Adult and Pediatric Adverse Events, Version 1.0, National Institutes of Health Division of AIDS, 2004.

19. Hubschen J M, Mihneva Z, Mentis A F, Schneider F, Aboudy Y, Grossman Z, Rudich H, Kasymbekova K, Sarv I, Nedeljkovic J, Tahita M C,Tarnagda Z, Ouedraogo J B, Gerasimova A G, Moskaleva T N, Tikhonova N T, Chitadze N, Forbi J C, Faneye A O, Otegbayo J A, Charpentier E, Muller C P. Phylogenetic analysis of human parvovirus B19 sequences from eleven different countries confirms the predominance ofgenotype 1 and suggests the spread of genotype 3b. Journal of Clinical Microbiology 2009, 47:3735-3738.

20. Servant A, Laperche S, Lallemand F, Marinho V, De 
Saint Maur G, Meritet J F, Garbarg-Chenon A. Genetic diversity within human erythroviruses: identification of three genotypes. Journal of Virology 2002, 76:9124-9134.

21. Pereira RFA, de Cássia R, Garcia NC, de Azevedo KML, Setu' bal S, de Siqueira MA, de Oliveira SA. Clinical features and laboratory findings of human parvovirus B19 in human immunodeficiency virus-infected patients. Mem Inst Oswaldo Cruz, Rio de Janeiro 2014,109(2): 168-173. 22. Aleru BO, Olusola BA, Faneye AO, Odaibo GN, Olaleye DO. Prevalence and Genotypes of Parvovirus B19 Among HIV Positive Children in Ibadan, Oyo State, Nigeria. Arch. Bas. App. Med. 2018, 6: 113-117.

23. Aghakhani, A., Mohraz, M., Azadmanesh, K. Moayedi-Nia S, Kazemimanesh M, Mamishi S, Banifazl M, Ramezani A. No evidence of persistent parvovirus B19 viremia among Iranian patients with HIV after a 1-year follow-up. Arch Virol 2016, 161: 1183.

24. Ferry T, Hirsche B, Dang T, MeylanP, Delhumeau C, Rauch A, Weber R, Elzi L, Bernasconi E, Schmid P, Calmy A. Infrequent Replication of parvovirus B19 and Erythrovirus Genotypes 2 and 3 among HIV-Infected Patients with Chronic Anemia. Journal of Clinical Infectious Diseases 2010, 50: 115-118.

25. Meidani M, Rezaei F, Maracy M R, Avijgan M, TayeriK. Prevalence, Severity and related factors of anemia in HIV/AIDS patients. Journal of Research in Medical Sciences 2012, 17:138-142.

26. Gyllensten K, Sonnenborg A, Jorup-Ronstrom C, Halvarsson M, Yun Z. Parvovirus B19 infection in HIV1 infected patients with anemia. Infection 1994, 22:356358.
27. Aguiar FS, Lopes DP, Bazin AR, Setúbal S, Cohen BJ, Nascimento JP. Human parvovirus B19 infection in HIV-positive patients. Rev Soc Bras Med Trop 2001, 34: 239-242.

28. Azadmanesh K, Mohraz M, Kazemimanesh M, Aghakhani A, Foroughi M, Banifazl M, Eslamifar A, and Ramezani A. Frequency and Genotype of Human parvovirus B19 Among Iranian Patients Infected With HIV. Journal of Medical Virology 2015. DOI: 10.1002/jmv.24169 29. Naides S J, Howard E J, Swack N S, True C A, Stapleton J T. Parvovirus B19 infection in human immunodeficiency virus type 1 - infected persons failing or intolerant to zidovudine therapy. Journal of Infectious Diseases 1993, 168: 101-105.

30. Chernak E, Cubbin G, Henry D, Naides S J, Hodinka R L, Macgregor R R, Friedman H M. Infection due to parvovirus B19 in pa $\neg$ tients infected with human immunodeficiency virus. Journal of Clinical Infectious Diseases 1995, 20: 170-173.

31. Van Elsacker-NieleA M W, Kroon F P, Van der Ende M E. Prevalence of parvovirus B19 Infection in Patients infected with Human Immunodeficiency Virus. Clinical Infectious Diseases 1996, 23:1255-60.

32. Bremner J A G, Cohen B J. Parvovirus B19 as a cause of anemia in human immunodeficiency virus-infected patients. Journal of Infectious Diseases 1994, 169: 938-939

33. Vernazza P L, Pfister LA, Siegl G, Cassinotti P. High seroprevalence of parvovirus B19 among patients infected with human immunodeficiency virus. Clin Infect Dis 1996, 22: 198-199. 